DOI: https://doi.org/10.46667/renbio.v13i1.314

\title{
Entre encontros e ensino de biologia e gêneros e sexualidades: sopros e insurgências de uma biologia menor
}

\author{
Between encounters and teaching of biology and genders and \\ sexualities: murmurs and insurgencies of a minor biology
}

\author{
Sandro Prado Santos ${ }^{1}$; Matheus Moura Martins ${ }^{2}$
}

\begin{abstract}
Resumo:
Este artigo apresenta dados de uma pesquisa cartográfica que se interessou pelas ressonâncias das experiências de pessoas trans aos territórios da educação em Biologia e que se materializou num caminhar entre os emaranhados do campo oficial do ensino de Biologia. Nesse contexto, temos como objetivo apresentar as potencialidades e as insurgências de um mapeamento dos movimentos efetuados nos ENEBIO e EREBIO. O sopro dos encontros nos convocaram ao agenciamento "Experiências de pessoas trans - Ensino de Biologia" que nos abriu espaços para pensarmos a educação em biologia enquanto territórios constituídos por linhas de diferentes naturezas, ritmos e direções, e, em que os gêneros e as sexualidades ecoam e funcionam na sua constituição, produzindo planos que coexistem em oscilações maiores e menores.
\end{abstract}

Palavras-chave: Educação em Biologia; Gênero; Sexualidade; Filosofia da diferença.

\begin{abstract}
:
This article presents data from a cartographic research that was interested in the resonances of the experiences of trans people to the areas of education in Biology and that materialized in a walk among the tangles of the official field of Biology education. In this context, our objective are to present the potentialities and insurgency of a mapping of the movements made in ENEBIO and EREBIO. The breath of the meetings summoned us to the agency "Experiences of trans people - Biology Teaching" that opened spaces for us to think about education in biology as territories constituted by lines of different natures, rhythms and directions, and, in which genders and sexualities echo and function in their constitution, producing plans that coexist in larger and minor oscillations.
\end{abstract}

Keywords: Biology Education; Gender; Sexuality; Philosophy of difference.

\footnotetext{
${ }^{1}$ Doutor em Educação - Universidade Federal de Uberlândia (UFU). Uberlândia, MG - Brasil. Professor adjunto

- Universidade Federal de Uberlândia (UFU). Uberlândia, MG - Brasil. E-mail: sandro.santos@ufu.br

${ }^{2}$ Licenciatura em Ciências Biológicas; Mestrando em Educação - Universidade Federal de Uberlândia (UFU). Uberlândia, MG - Brasil. E-mail: matheus.moura@ufu.br

Submetido em: 01/05/2020 - Aceito em: 16/06/2020
} 
DOI: https://doi.org/10.46667/renbio.v13i1.314

"[...] pensar nas janelas que o ensino de Biologia permite abrir é também trazer outras representações culturais e outros sujeitos para dialogar". (SELLES,1 2014, p. 22).

\section{1 "Abrindo janelas" ...}

Este texto apresenta dados de uma pesquisa de doutorado em que mapeamos, a partir de uma perspectiva cartográfica (DELEUZE; GUATTARI, 2011), as possíveis ressonâncias que a aliança - Experiências de pessoas trans - Ensino de Biologia - pode produzir aos territórios da Educação em Biologia. (SANTOS, 2018). Ressaltamos que utilizamos "experiências de pessoas trans" para não fazer referência direta a uma denominação médica/patológica e por não referenciar um arranjo unívoco entre as muitas possibilidades relacionadas aos deslocamentos de gênero das pessoas trans. Reafirmamos a polifonia das pluralidades de experiências possíveis com/nos corpos, gêneros, sexualidades e desejos. (JESUS, 2012; SANTANA; POLIZEL; MAIO, 2016).

No entanto, a referida aliança não estava dada antes da investigação, preexistente, ou que já estava planejada a priori, foi sendo produzida ao longo do movimento da pesquisa em que os atravessamentos entre sexualidades, gêneros e o Ensino de Biologia fizeram atualizar as participações nos Encontros Nacionais do Ensino de Biologia (ENEBIO), Encontros Regionais de Ensino de Biologia (EREBIO) da Associação Brasileira de Ensino de Biologia (SBEnBio) ${ }^{3}$, bem como as incursões nas produções oriundas de tais encontros no campo oficial do ensino de Biologia.

No campo encontramos sinalizações da importância de sensibilidades, insurgências, experimentações e ressonâncias de temas e sujeitos 'das margens ${ }^{4}$ nas discussões e diálogos curriculares com o Ensino de Biologia como possibilidade de potencializar "[...] novas perspectivas que podem contribuir para a formação e atuação docente do professor de Ciências e Biologia”. (BARZANO, 2016, p. 105).

Com isso, nos interessamos por um caminhar entre os emaranhados do campo oficial do ensino de Biologia, os movimentos efetuados e as linhas estendidas por reflexões, práticas e estudos realizados com os atravessamentos dos campos do gênero e da sexualidade a partir das seguintes problemáticas: O que o campo oficial traz acerca de outros modos culturais de se pensar gêneros e sexualidades, bem como de outros sujeitos para dialogar? Quais janelas que o

\footnotetext{
${ }^{3}$ A SBenBio é uma sociedade civil de caráter científico e cultural, sem fins lucrativos, que tem por finalidade promover o desenvolvimento do Ensino de Biologia e da pesquisa em Ensino de Biologia entre os/as profissionais desse campo de conhecimento. A sociedade foi criada em 1997 no VI Encontro de Perspectivas do Ensino de Biologia realizado na Faculdade de Educação da Universidade de São Paulo (FEUSP). No entanto, o primeiro encontro nacional foi datado em 2005 no Rio de Janeiro/RJ. Ver. Revista da Sociedade Brasileira de Ensino de Biologia, ano 1, número 0, ago. 2005.

${ }^{4}$ Barzano (2016) ao evocar a imagem da capa da Revista Nova Escola 'Vamos falar sobre ele? Como lidar com um aluno que se veste assim? Uma reflexão sobre sexualidade e gênero', ano 30, n. 279, fev. 2015 se deparou com os desafios da formação e da prática de professores/as de Biologia, pois o tema gera desassossego, desestabilização e um silêncio ensurdecedor.
} 
ensino de Biologia permite abrir nas discussões de gêneros e sexualidades? No entrelaçamento (gênero e sexualidade) quais as potencialidades e as insurgências na composição de outros desenhos e configurações da Educação em Biologia?

Desse modo, esse texto tem como objetivo apresentar as potencialidades e as insurgências, ao campo da Educação em Biologia, a partir de um mapeamento dos movimentos efetuados nos ENEBIO e EREBIO no âmbito das discussões de gênero e sexualidade.

\section{Um des-caminhar investigativo}

Na investigação de doutorado, utilizamos a perspectiva cartográfica (DELEUZE; GUATTARI, 2011) como um modo de dialogar e/ou transitar com os territórios da Educação em Biologia, constituindo um campo de pesquisa polifônico.

A cartografia compõe um ensaio de uma forma de se fazer pesquisa que opera a partir de um fora na produção de mapas, sempre abertos, de relações de forças, mapas de densidade e mapas de intensidade. Ela é marcada como um modo de desenhar diagramas, traçando e acompanhando movimentos de poder, jogos de verdade, a composição de dispositivos, linhas de força e enfrentamentos. $\mathrm{O}$ ato de cartografar se presta ao enfrentamento dos dispositivos, no desemaranhar suas linhas, produzindo rupturas e resistências em seus modos de operação. (PRADO-FILHO; TETI, 2013).

Aqui o foco, da composição do desenho cartográfico da tese, será nas linhas produzidas entre sexualidades, gêneros e o Ensino de Biologia a partir das participações nos ENEBIO, EREBIO até início de $2018^{5}$, ano defesa da referida tese, bem como nas incursões pelas produções oriundas dos encontros nacionais, aqui a fonte de investigação empírica foi os levantamentos já realizados por Etter et al (2014), Pinho; Bastos (2016) e Santos; Martins (2017).

\footnotetext{
${ }^{5}$ Referimos aos eventos: I ENEBIO e III EREBIO - Regional 02 (RJ/ES) - 2001; II ENEBIO e I EREBIO da Regional 04 (MG/TO/GO/DF) - 2007; III ENEBIO e IV EREBIO da Regional 05 (Nordeste) e V Congresso Iberoamericano de Educación en Ciencias Experimentales - 2010; IV ENEBIO e II EREBIO - Regional 04 - 2012 ; V ENEBIO e II EREBIO da Regional 01 (SP/MT/MS) - 2014; VI ENEBIO e o VIII EREBIO da Regional 03 2016; II EREBIO do Nordeste e $5^{\circ}$ Encontro Paraibano de Ensino de Ciências - 2006; III EREBIO - Regional 01 - 2017; IV EREBIO - Regional 04 - 2017; VIII EREBIO - Regional 02 - 2017; VII EREBIO - Regional 05 - 2017.
} 


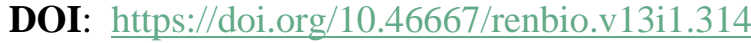

\section{Os Encontros Nacionais e Regionais do ensino de Biologia: espaços formativos e a produção científica}

As investigações de Etter et al (2014), Pinho; Bastos (2016) e Santos; Martins (2017) que se ocuparam do mapeamento dos sentidos de sexualidade e de gênero nas produções do campo oficial dos ENEBIO têm mostrado um território em que corpos, gêneros e sexualidades estão, majoritariamente, codificados, estriados e amarrados na essência; racionalidade; isolamento e imobilidade. Nas produções há uma recorrência de "[...] uma relação mimética entre sexo e gênero, uma continuidade entre corpos sexuados e gêneros inteligíveis, isto é, ser homem alinhado exclusivamente a corpos masculinos e ser mulher colado aos corpos femininos". (SANTOS; MARTINS, 2017, p. 6).

Encontramos, no I ENEBIO ${ }^{6}$, apenas os trabalhos que têm como focos a saúde, a discussão centrada no campo biomédico e a produção de materiais didáticos. De modo igual são os trabalhos apresentado no II Encontro ${ }^{7}$ realizado na cidade de Uberlândia/MG em 2007. Como resultado do I Encontro houve a publicação do livro - "Ensino de Biologia: conhecimentos e valores em disputa" que reúne os textos das mesas redondas e conferência dessa edição. A obra é estruturada em cinco partes, sendo que a quarta parte - Que ser humano cabe no Ensino de Biologia? ${ }^{8}$ - nos lançam, pioneiramente por meio dessas três autoras, na produção de sentidos para o humano e suas ressonâncias no campo do corpo e sexualidade que as práticas de ensino de Biologia realizam.

Encontramos também na obra "Ensino de Biologia: fios de desafios na construção de saberes", organizada pelo $2^{\circ}$ EREBIO do Nordeste e $5^{\circ}$ Encontro Paraibano de Ensino de Ciências no ano de 2008, o texto "As práticas e as produções curriculares das Ciências e Biologia sobre o corpo no Ensino Fundamental e Médio" da professora Elenita Pinheiro. O texto trouxe uma reflexão sobre as propostas e práticas curriculares da temática do corpo que circulam nos espaços escolares, problematizando a destituição do corpo de seus contextos culturais e fragmentados.

Como desdobramento do II ENEBIO, encontramos com o Ensino de Biologia: histórias, saberes e práticas formativas. Nele, não há nenhum capítulo com enfoque no tema gênero e sexualidade. O trabalho de Elenita Pinheiro de Queiroz Silva e Graça Aparecida Cicillini (2009) 'Cultura, educação e produção curricular na Biologia: o tema corpo humano como pretexto' aproximou a discussão Biologia, cultura e ensino do corpo humano.

\footnotetext{
${ }^{6}$ I ENEBIO e III EREBIO Biologia - Regional 02 RJ/ES. Realizado na Faculdade de Educação da Universidade Federal do Rio de Janeiro - RJ em 2005. O tema central do evento foi - Ensino de Biologia: conhecimentos e valores em disputa.

${ }^{7}$ II ENEBIO e I EREBIO da Regional 04 (MG/TO/GO/DF). Realizado de 12 a 15 de Agosto de 2007. O tema geral foi - "Os 10 anos e o Ensino de Biologia no Brasil: histórias entrelaçadas".

${ }^{8} \mathrm{O}$ conjunto de textos é: Que corpo/ser humano habita nossas escolas?' (Silvia Luzia Frateschi Trivelato); Esse corpo das Ciências é o meu? '(Elizabeth Macedo) e Quando o corpo é uma (des)construção cultural' (Elenita Pinheiro de Queiroz Silva).
}

REnBio - Revista de Ensino de Biologia da SBEnBio - ISSN: 1982-1867 - vol. 13, n. 1, p. 141-152, 2020 
Em sua terceira edição 9 "Temas polêmicos e o Ensino de Biologia" o evento estimulou o debate acerca das diversas temáticas que circulam socialmente e suscitam debates sobre a Biologia e seu ensino, tais como aquelas referentes a valores morais, sociais, éticos, estéticos e políticos. A presença de temáticas no cotidiano social e na escola, que se expressam curricularmente como questões de gênero e sexualidade, educação moral, conflitos religiosos, desafios da educação sócio-ambiental, biotecnologias e relações sócio-políticas, entre vários, são instigantes para aprofundar seus sentidos e debatê-las nas fronteiras disciplinares que vem se construindo ao longo da história do ensino de Biologia. (SELLES, 2010).

No IV e V ENEBIO resgatamos os debates de dois painéis temáticos - "Gênero e Sexualidade" e "Corpo, Gênero, sexualidade nos currículos de Biologia"" - e também, da mesa redonda "Corpo, Gênero, Sexualidades: políticas educacionais e o ensino de Ciências e Biologia" 12 . Na quarta edição o minicurso "Corpo, Gênero e Sexualidade nos contextos educacionais de aulas de Ciências e Biologia" 13 com as professoras Néli Suzana Britto, Marcela Olinto, Marina Nunes Teixeira Soares (UFSC/SEE-DF/UnB). $\mathrm{Na} 6^{\circ}$ edição do ENEBIO o minicurso intitulado "Educação para os gêneros e as sexualidades: para além dos dispositivos biológicos", oferecido pela professora Fabiana Aparecida de Carvalho (UEM/PR) e alunos/as do grupo de pesquisa coordenado por essa professora ${ }^{14}$. Importante destacar que nessa edição ocorreu a oficina "Corpo - corpo, gênero e sexualidade - refletindo sobre nós mesmos/as" que dentre os/as proponentes estava Naomi Neri que se autoidentificava como mulher trans.

\footnotetext{
${ }^{9}$ III ENEBIO e IV EREBIO da Regional 05 (Nordeste) e V Congresso Iberoamericano de Educación en Ciencias Experimentales foi realizado na Universidade Federal do Ceará em Fortaleza de 10 a 13 de outubro de 2010. O tema geral do evento foi "Temas Polêmicos e o Ensino de Biologia".

${ }^{10}$ IV ENEBIO e II EREBIO Regional 04 ocorreu de 18 a 21 de setembro de 2012, na Universidade Federal de Goiás - Goiânia/GO. O evento teve como tema central "Repensando a experiência e os novos contextos formativos para o Ensino de Biologia". O painel temático foi conduzido pelos/as professores/as e pesquisadores/as Marcos Lopes (UESB) e Néli Britto (UFSC) e mediada por Adriana Mohr (UFSC).

${ }^{11}$ V ENEBIO e II EREBIO da Regional 01, ocorreu de 8 a 11 de setembro de 2014, no Instituto de Biociências da Universidade de São Paulo - São Paulo/SP. O evento teve como tema central Entrelaçando histórias, memórias e currículo no Ensino de Biologia. O painel temático foi conduzido pelas professoras e pesquisadoras Paula Regina Costa Ribeiro (FURG/RS) e Mirian Pacheco Silva (UFABC/SP).

${ }^{12}$ VI ENEBIO e o VIII EREBIO da Regional 3 ocorreu no período de 02 a 05 de Outubro de 2016, no Câmpus da Universidade Estadual de Maringá (UEM), em Maringá - Paraná. O evento teve como tema central "Políticas Públicas Educacionais - Impacto e Propostas ao Ensino de Biologia". A mesa redonda foi composta pelos/as professores/as e pesquisadores/as Mateus Luiz Biancon (UENP) Marcos Lopes (UESB) Vera Lúcia Bahl de Oliveira (UEL).

${ }^{13}$ Nesse evento, também, ocorreram outros minicursos e oficinas com essa temática: "Sexualidade e Cinema: diálogos que podem interessar as Ciências e a Biologia na escola": (Elenita Pinheiro de Queiroz Silva; Fátima Lúcia Dezopa Parreira e Patricia Lemos Campos - UFU); "Corpo, gênero e sexualidade no ensino de Ciências Naturais: um olhar para a formação cidadã: (Renata do Nascimento Jucá; Vanessa Batista Lins; Maryellen Cristina Tenório Alves; Evandro Coelho dos Santos Filho e Daniella Y. de Araujo - UFAL).

${ }^{14}$ Nessa edição também ocorreram oficinas, a saber: "Corpo - corpo, gênero e sexualidade - refletindo sobre nós mesmos/as": (Tamires Tolomeotti Pereira (UFPR); Mateus Oka de Farias e Naomi Neri - UEM); "(Des)construindo corpos: tateando Biologias e culturas": (Mariane Schmidt da Silva; Ana Cláudia da Motta Coelho de Rezende Morato; Vinícius Abrahão de Oliveira - UFU).
} 
DOI: https://doi.org/10.46667/renbio.v13i1.314

Até a $5^{\text {a }}$ edição dos encontros nacionais cartografamos um desenho da existência ou ocorrência de um silenciamento das discussões das experiências de pessoas trans alinhavadas com o Ensino de Biologia. Não encontramos nessas produções possibilidades de borramentos ou ocupação das fronteiras de gênero, sedimentando um currículo das margens pouco sensível, pouco inquieto, mas muito sabido às lógicas/saberes universais. (BARZANO, 2016).

Nesse contexto, reafirmamos os silenciamentos ensurdecedores que nos provocaram incômodos por vivenciarmos experiências outras que (re)existem ao corpo, ao gênero e sexualidade assumida por uma Biologia que se presta ao silêncio das multiplicidades no espaço escolar. Nas investigações do Ensino de Biologia "[...] há uma grande lacuna no interesse ao estudo investigativo sobre 'temas e sujeitos das margens' [...]”. (BARZANO, 2016, p. 114). O autor vê com otimismo que as janelas estão se abrindo, diante do:

[...] crescimento de pesquisas destes temas e sujeitos das margens e isto tem sido constatado nas últimas três edições do ENEBIO o que fomentando o debate de temas voltado para aspectos histórico-social, cultural e político proferido nas mesasredondas e painéis temáticos. (p. 119).

Foi na $6^{a}$ edição do ENEBIO que aconteceu a apresentação do relato de experiência 'Concepções de professores de Ciências e Biologia do município de Maringá, Paraná, sobre transexualidade' no eixo temático 'Formação de Professores de Ciências e Biologia'. Foi apresentado por Naomi Neri Santana, uma aluna transexual licenciada em Ciências Biológicas pela Universidade Estadual de Maringá/PR.

Os/as autores/as Naomi Neri Santana; Alexandre Luiz Polizel e Eliane Rose Maio (2016) ocuparam-se nessa produção sobre as representações de professores/as de Ciências e Biologia sobre a transexualidade. Representações amarradas em uma linearidade de sexogênero-sexualidade, determinista e essencialista, pautada na biologia dos corpos. Apontando, nesse sentido, para o que os/as autores/as chamam de "uma defasagem na formação de professores/as e nos currículos no que tange a temática transexualidade" (p. 5054) e um reducionismo ao considerar as experiências trans desapartadas de uma "[...] rede de significações se mesclam, atravessam e hibridizam constantemente". (SANTANA; POLIZEL; MAIO, 2016, p. 5054).

Nesse mesmo evento foi apresentado o relato da pesquisa de Neilton dos Reis e Raquel Pinho (2016) intitulado 'Ensino de Biologia e gênero: o que dizem as narrativas não-binárias?' que teve como propósito (re)pensar os enlaces entre Ensino de Biologia, gêneros não-binários e estudos queer. No que tange as aulas do Ensino de Biologia, as narrativas apontaram para a forma reducionista que os temas de gênero e sexualidade são abordados; os silenciamentos impostos às diferenças de gênero e sexualidades, invisibilizando e patologizando as dissidências de sexualidade e gênero. 
DOI: https://doi.org/10.46667/renbio.v13i1.314

Nesse percurso cartográfico, destacamos que as produções e os espaços formativos durante os encontros provocaram tensionamentos nas evidências de um fazer amarrado em conteúdos biomédicos e desconectados dos espaços culturais que ocupa, produzindo pistas, fissuras, movimentos, possibilidades para outros deslocamentos, racionalidades e tensões criativas no encontro com o Ensino de Biologia.

Sendo assim, fissuras no campo do Ensino de Biologia têm sido produzidas. Uma delas ocorreu no VII EREBIO - Regional 5 - Nordeste na Universidade Regional do Cariri (URCA) na cidade do Crato/CE, em setembro de 2017. Esse movimento ocorreu em dois momentos. O primeiro foi uma mesa redonda intitulada 'Corpos flutuantes entre gênero, sexualidade e raça' com a professora Alice Alexandre Pagan da Universidade Federal de Sergipe, e o professor Marcos Lopes de Souza, da Universidade Estadual do Sudoeste da Bahia. O outro momento foi na conferência de encerramento do evento 'Biologia na escola: corpos, gêneros $e$ sexualidades', com a professora Luma Nogueira de Andrade, que se autoidentifica como travesti.

Esses momentos foram potentes aos territórios da educação em biologia, pois perturbaram as sedimentações normativas do campo do gênero, do corpo e da sexualidade, acionando e visibilizando "outras" biologias que insistem e disputam a não invisibilidade nas diretrizes curriculares e nos textos pedagógicos.

As linhas desse mapeamento, aqui esboçadas, evidenciaram expansões, fraturas, rupturas, mudanças de ênfases, conquistas e aberturas nos quadros convencionalmente produzidos nesse campo, nos instigando a fazer outras criações, e pensar o (im)pensado ou o (in)suspeitável no Ensino de Biologia. O que foi possível enunciar e dizer a partir desses encontros? Quais pistas foram sendo sinalizadas para pensar o movimento da investigação da referida tese? Quais pistas foram possíveis delinear para compor outros desenhos e configurações da Educação em Biologia?

\section{0 sopro dos encontros nos territórios da Educação em Biologia}

Os encontros com o campo oficial do ensino de Biologia nos dispuseram a pensar e a insistir na aproximação das experiências de pessoas trans e biologia, eles foram produzindo um deslocamento dos olhares daquilo que sempre foi considerado como central, nuclear, essencial para se entender o funcionamento da Biologia, para aquilo que era descrito como marginal, menor, patológico, anormal e fronteiriço, ou seja, considerado como um 'inimigo' nas margens de sentido. Em 'Uma Cartografia das margens' Albuquerque-Júnior, Veiga-Neto e SouzaFilho (2011) apontaram que

[...] Foucault teria deslocado seu olhar para as bordas constitutivas da racionalidade ocidental ao se dedicar a estudar a desrazão, a loucura, a anormalidade, a monstruosidade, a sexualidade, o corpo, a literatura, os ilegalismos, os infames, tudo aquilo que a racionalidade moderna excluiu, desconheceu, definiu como passível de punição, de normalização e medicalização. (p. 9). 


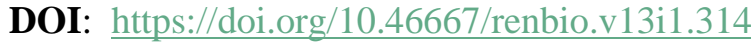

Com isso, Foucault considerava que os delineamentos e contornos de uma sociedade se dão a partir do que ela "[...] joga para as margens é o que constitui seus limites, as suas fronteiras e é justamente o que a define [...]”. (ALBUQUERQUE-JÚNIOR, VEIGA-NETO E SOUZAFILHO, 2011, p. 9-10). Nesse sentido aciona a potencialidade de experiências consideradas marginais na produção de processos de insurgências de modos outros de existência.

As experiências do fora, das margens, dos limites, das fronteiras, seriam experiências que permitiriam cartografar novos desenhos, novas configurações para o acontecer de uma dada sociedade. Como o saber é perspectivo, esse olhar das margens permite constituir outras visibilidades e outras dizibilidades sobre qualquer tema ou problema que se queira colocar para o conhecimento. (ALBUQUERQUE-JÚNIOR; VEIGA-NETO; SOUZA-FILHO, 2011, p. 10).

Nesse sentido, apostamos nas (in)constâncias que atravessam as experiências das pessoas trans para mobilizar um encontro potente no/com o Ensino de Biologia, na tentativa de produzir desenhos outros; configurações outras para movimentá-lo e povoá-lo com outras instâncias que permitissem que um Ensino de Biologia outro, também, funcionasse na produção de "[...] saberes e tecnologias que possibilitam a educação da recusa aos modelos fixos e prédeterminados das vivências das feminilidades, masculinidades e da orientação sexual". (SILVA, 2017, s/p). Passamos então a agenciar o encontro das experiências de pessoas trans ensino de Biologia (SANTOS, 2018), tencionando:

[...] a Educação em Biologia com a potência do sopro das experiências de pessoas trans, de modo a desfazer [...] aquilo que se encontrava estratificado em nós, ou aquilo que vemos se repetir em ditos e vistos nas aulas de Biologia, abrindo espaço [...] que seja possível dizer, sentir, viver e [...] esburacar o que se vê e o que se diz de corpos, gêneros e sexualidades. (SANTOS; MARTINS, 2019, p. 102).

Uma experimentação provocativa, fascinante, sedutora, afetiva que (des)arruma o que já foi pensando no Ensino de Biologia. Provoca perplexidades, admirações, surpresas e indignações. A aposta foi a de que essa criação

[...] em seus múltiplos caminhos e trajetos, nos faz olhar e encontrar trilhas diferentes a serem perseguidas, possibilidades de transgressões em emolduramentos que supomos permanentes, em quadros que nos parecem fixos demais, em direções que nos parecem por demais lineares. (PARAÍSO, 2005, p. 79).

Uma das ressonâncias produzidas/disparadas no encontro - Experiências de pessoas trans - Ensino de Biologia - foi a aproximação e conexão com a perspectiva das filosofias da diferença (DELEUZE; GUATTARI, 2011, 2012), produzindo deslocamentos na robustez epistemológica da bio-logia nos convocando a outros olhares, traçados, lugares e (re)composições. 
DOI: https://doi.org/10.46667/renbio.v13i1.314

A partir desses contextos foi possível pensar a Educação em Biologia, na esteira de Deleuze e Guattari (2012), enquanto territórios constituídos por linhas de diferentes naturezas, ritmos e direções, que podem normatizar e fixar modos existenciais ou investir em outras linhas que criam territórios outros, singularizando e vitalizando as experiências. Podemos tomá-la como um território espacial subjetivo que tem a sua geografia, sua cartografia e seu diagrama de forças que permite (des)territorializações de modos de ser e estar das pessoas (DELEUZE, 2013).

Com essa perspectiva, entendemos a educação em Biologia como um “[...] território político, ético e estético incontrolável que, se é usada para regular e ordenar, pode também ser território de escapes de todos os tipos, no qual se definem e constroem percursos inusitados [...] trajetos grávidos de esperança a serem percorridos" (PARAÍSO; CALDEIRA, 2018, p. 14).

Nesse sentido, reforçamos que as discussões de gênero e sexualidade ecoam e funcionam desde dentro na organização e constituição do jogo que está na ordem das coisas da educação em Biologia, (RANNIERY; LEMOS, 2018), produzindo-a enquanto territórios que oscilam entre dois planos, que atuam, funcionam e coexistem ao mesmo tempo nas superfícies territoriais: de um lado, as superfícies de estratificação, normalizações e (órgão)nização, e, por outro, o plano no qual eles resistem, insistem, criam e fluem como corpos intensivos. Nesse movimento, temos tomado e pensado a Educação em Biologia, no diálogo com os gêneros e as sexualidades, nos/com seus ditos e vistos maiores e menores. Aproximações com os estudos das filosofias das diferenças (DELEUZE; GUATTARI, 2011; 2012), e, com a noção de educação maior e educação menor (GALLO, 2016), possibilitaram pensarmos uma Educação em Biologia maior e menor.

Os ditos e vistos maiores dispõem de elementos que ensinam sobre os corpos, gêneros e sexualidades a partir de campos neutros, não políticos, desapartados dos processos de socialização e sedimentados na universidade do organismo bio-lógico. Um campo que amarra narrativas estáticas e com fronteiras fixas que adensam um plano de operação na definição do corpo por seus órgãos e suas funções. (DELEUZE; GUATTARI, 2012). Ela produz explicações e/ou descrições, primeiras e únicas, acerca do que (é) o gênero e a sexualidade. Proscreve-os do campo da experiência, circunscrevendo-os numa organização estrutural orgânica, negativando os seus movimentos mediante a antecipação de uma significação última, original e essencial. Os demais sentidos de gêneros e sexualidades são derivados e submetidos à primazia das explicações biológicas.

A educação em Biologia menor está implicada num regime que desfaz uma totalidade orgânica que encerra subjetividades e experiências do sujeito. Uma máquina de resistência (GALLO, 2016) que arranca o lugar fixador dos corpos, gêneros e sexualidades, modificandoos " $n$ " vezes, mergulhando-os num campo de ligações e operações com o campo biológico, social, histórico, dentre outros. Uma biologia menor produz um processo de afirmação e abertura de reinvenções de modos singulares dos corpos, gêneros e sexualidades, possibilitando esburacamentos e/ou fissuras em sua educação maior. 
DOI: https://doi.org/10.46667/renbio.v13i1.314

Isso nos ofereceu a impossibilidade de lidar e fechar o gênero e sexualidade na Educação em Biologia em explicações tranquilas marcadas pela ausência de nuances e sem inconstâncias, ou em uma estabilidade pretensiosamente biológica. Tal operação nos abriu espaços, para o menor, uma biologia menor de afirmação dos gêneros e sexualidades. Espaços para que a Educação em Biologia possa inventar-se, aprendendo modos singulares de gêneros e sexualidades, produzindo um funcionamento menor da biologia que esburaca a sua educação maior que impõe um caminho único aos corpos, gêneros e sexualidades (como o mais correto, como 'normal') e desapartam os gêneros e sexualidades como constituintes e constitutivos do jogo que está na ordem das coisas da Educação em Biologia.

Desse modo, algumas inquietações ficam nos rondando e abrindo possibilidades de outros investimentos investigativos nos territórios da educação em biologia: De que modo abrir espaços na biologia maior? Como abrir espaços para outras possibilidades de corpos, gêneros e sexualidades? Seria possível fazer alianças com o menor? Como agenciar um funcionamento menor da biologia que esburaca a sua educação maior? A quem se aliar? Com isso, temos interessado pelos devires e pelas fissuras que arrastam os ditos da educação em biologia para lugares outros, lugares que ela ainda des-conhece, e, pelas suas potencialidades de inventar outras educações em biologia.

\section{Para não fechar janelas...}

Buscamos com esta escrita, experimentar com os movimentos, rastros, (des)encontros, as linhas e os traçados efetuados nos ENEBIO e EREBIO no âmbito das discussões de, gênero e sexualidade, na tentativa de espraiar as poeiras que se ergueram desses e fazer com que se assentem em outros lugares, distante daqueles em que estão acostumadas a serem sedimentadas, inventando outras possibilidades e educações em biologia.

Consideramos a potência do agenciamento "experiências de pessoas trans - ensino de Biologia", pois ele aciona "outras" biologias dentro dos territórios concretos, sedimentados de normas. "Biologia(s)" invisibilizada(s) nas diretrizes curriculares, nos textos pedagógicos, nos planos, projetos e propostas de ensino, nas aulas e nos livros didáticos dos currículos escolares de Ciências e Biologia.

Enfim, os encontros disparam nessa escrita a pensar a educação em biologia como territórios movediços, compostos por ditos e vistos sempre provisórios e em disputa, correndo o risco, a todo o momento, de esburacarem e se desmancharem nas fissuras, e são n(as) fissuras que interessamos e apostamos na existência de possiblidades de inventar outras educações em biologia, de outros modos e desde outros lugares, insurgências de uma biologia menor. 
DOI: https://doi.org/10.46667/renbio.v13i1.314

\section{Referências}

ALBUQUERQUE-JÚNIOR, Durval Muniz de.; VEIGA-NETO, Alfredo.; SOUZA-FILHO, Alípio de. Uma cartografia das margens. In: ALBUQUERQUE-JÚNIOR, Durval Muniz de.; VEIGA-NETO, Alfredo.; SOUZA-FILHO, Alípio de. (Org.). Cartografias de Foucault. 2. ed. Belo Horizonte: Autêntica, 2011, p. 9-12.

BARZANO, Marco Antonio Leandro. Currículo das margens: apontamentos para ser professor de Ciências e Biologia. Revista Educação em Foco, Juiz de Fora/MG, v.21, n.1, p. 105-124, mar./jun. 2016.

DELEUZE, Gilles. Conversações. 3.ed. Tradução de Peter Pál Pelbart. São Paulo: Ed.34, 2013.

DELEUZE, Gilles.; GUATTARI, Félix. Mil Platôs, v.1. Tradução de Ana Lúcia de Oliveira, Aurélio Guerra Neto e Célia Pinto Costa. São Paulo: Ed. 34. 2011.

DELEUZE, Gilles.; GUATTARI, Félix. Mil Platôs, v.3. Tradução de Aurélio Guerra Neto, Ana Lúcia de Oliveira, Lúcia Cláudia Leão e Suely Rolnik. São Paulo: Ed. 34. 2012.

ETTER, Fernanda. et al. Sentidos de sexualidade em produções acadêmicas: Investigando os anais dos Encontros Nacionais de Ensino de Biologia (2005-2012). Revista SBenBio, Niterói, v. 7, p. 2085-2096, 2014.

GALLO, Silvio. Deleuze \& Educação. 3.ed. Belo Horizonte: Autêntica, 2016.

JESUS, Jaqueline Gomes de. Orientações sobre a população transgênero: conceitos e termos. Brasília: Autor, 2012.

MARANDINO, Martha.; SELLES, Sandra Escovedo.; FERREIRA, Márcia Serra.; AMORIM, Antônio Carlos Rodrigues (Org.). Ensino de Biologia: conhecimento e valores em disputa. Niterói: EdUFF, 2005. p. 121-130.

PARAÍSO, Marlucy Alves. Currículo-mapa: linhas e traçados das pesquisas pós-críticas sobre currículo no Brasil. Educação \& Realidade, v.30, n.1, p. 67-82, jan./jun. 2005.

PARAÍSO, Marlucy Alves; CALDEIRA, Maria Carolina da Silva. Apresentação. In: PARAÍSO, Marlucy Alves.; CALDEIRA, Maria Carolina da Silva. (Org.). Pesquisas sobre currículos, gêneros e sexualidades. Belo Horizonte: Mazza, 2018, p. 13-21.

PINHO, Raquel.; BASTOS, Felipe. Sentidos de sexualidade nos anais dos Encontros Regionais de Ensino de Biologia RJ/ES (2001-2015). Revista da SBEnBio, Maringá, PR, n.9, 2016.

PRADO-FILHO, Kleber.; TETI, Marcela Moltalvão. A cartografia como método para as Ciências Humanas e Sociais. Barbarói, Santa Cruz do Sul, n.38, p. 45-59, jan./jun. 2013. 
RANNIERY, Thiago.; LEMOS, Paula Cunha. de. Gênero pode ser uma categoria útil para o ensino de Biologia? In: VILELA, Mariana Lima et al. (Org.). Aqui também tem currículo! Saberes em diálogo no ensino de biologia. Curitiba: Prismas, 2018. p. 65-86. ISBN: 978-85537-0044-8.

REIS, Neilton dos.; PINHO, Raquel. Ensino de Biologia e gênero: o que dizem as narrativas não-binárias? Revista da SBEnBio, n.9, 2016, p. 3716-3727.

SANTANA, Naomi Neri.; POLIZEL, Alexandre Luiz; MAIO, Eliane Rose. Concepções de Professores de Ciências e Biologia no município de Maringá, Paraná, sobre transexualidade.

Revista da SBEnBio, n.9, 2016, p. 5054-5064.

SANTOS, Sandro Prado. Experiências de pessoas trans - ensino de Biologia. 2018. 289 f. Tese (Doutorado em Educação) - Universidade Federal de Uberlândia, Uberlândia, 2018.

SANTOS, Sandro Prado.; MARTINS, Matheus Moura. Configurações do campo do ensino de biologia e suas composições com as transexualidades. In: SIMPÓSIO INTERNACIONAL EM EDUCAÇÃO SEXUAL - SABERES/TRANS/VERSAIS CURRÍCULOS IDENTITÁRIOS E PLURALIDADES DE GÊNERO, 5., Maringá, 2017. Anais... Maringá, PR, 2017, p. 1-8.

SANTOS, Sandro Prado.; MARTINS, Matheus Moura. Corpos trans e a educação em Biologia: des-territorializações e conexões com a filosofia da Diferença. In: SEMINÁRIO CONEXÕES, 8., 2019, Campinas. Anais... Campinas, SP: UNICAMP/FE, 2019, p. 89-90.

SELLES, Sandra Escovedo. Apresentação. Revista de Ensino de Biologia da Associação Brasileira de Ensino de Biologia (SBenBio) - Temas polêmicos e Ensino de Biologia, v. 3, Campinas, SP: 2010.

SELLES, Sandra Escovedo. Desafios da formação e da prática de professores de Biologia: abrindo janelas. In: BARZANO, Marco Antônio Leandro.; FERNANDES, José Artur Barosso.; FONSECA, Lana Cláudia de Souza.; SHUARTZ, Marilda. (Org.). Ensino de Biologia: experiência e contextos afirmativos. Goiânia: Índice, 2014, p. 13-26.

SILVA, Elenita Pinheiro de Queiroz. O que a escola e a universidade têm a ver com a vida da população LGBTQI? Jornal da UFU, jul./ago. 2017, n. 176. Disponível em: comunica.ufu.br. Acesso em: 30 de setembro de 2017.

SILVA, Elenita Pinheiro de Queiroz; CICILLINI, Graça Aparecida. Cultura, educação e produção curricular na Biologia: o tema corpo humano como pretexto. In: SELLES, S. E. et al. (Org.). Ensino de Biologia: histórias, saberes e práticas formativas. Uberlândia: EDUFU, 2009, p. 149-172. 